\title{
THE USE OF FUZZY SYSTEMS FOR FORECASTING THE HARDENABILITY OF STEEL
}

The goal of the research carried out was to develop the fuzzy systems, allowing the determination of the Jominy hardenability curve based on the chemical composition of structural steels for quenching and tempering. Fuzzy system was created to calculate hardness of the steel, based on the alloying elements concentrations, and to forecast the hardenability curves. This was done based on information from the PN-EN 10083-3: 2008. Examples of hardenability curves calculated for exemplar steels were presented. Results of the research confirmed that fuzzy systems are a useful tool in evaluation the effect of alloying elements on the properties of materials compared to conventional methods. It has been demonstrated the practical usefulness of the developed models which allows forecasting the steels' Jominy hardenability curve.

Keywords: computational material science, artificial intelligence methods, materials design steels, modelling, simulation

\section{Introduction}

Steel products are and will be - in the foreseeable term necessary for the development of the basic spheres of modern society, ie traditional sectors, such as: design and construction, transport, energy (including renewable energy), machinery and devices.

Engineering industry in many EU countries is strongly associated with the global market. Pricing pressures, technological advances and increased activity of companies from Asian countries necessitate flexibility and the need to adapt to the expectations of the client, providing the expected high quality product at a competitive price.

In recent decades, the European steel industry maintained a competitive advantage over other producers by improving efficiency, innovative products and significantly increase productivity. The development of new cost-effective technology must go hand in hand with the improvement of the competitiveness of European steel companies in relation to their global competitors. Reduce the consumption of energy and raw materials in the production will lead to lower costs, making the European steel industry more competitive.

Long-term studies concerning the implementation of the production and placing on the market of new products in the period up to year 2030 should focus on completely innovative solutions, leading to a new quality in comparison to currently available. In particular, research should be directed to:

1. Obtaining a high level of performance, with a minimum of alloying elements [1-4],

2. Reduction of the specific density of the steel product or a composite containing steel [5-6],

3. Increased resistance to degrading environments [7-11],
Analysis of the current market situation in the EU shows the following prospects structural steel and machine:

1. Developing the knowledge base of the current state and projected growth of the markets in which they are or may be supplied goods produced by domestic steel industry.

2. Weather assortment structure and size of the steel market, taking into account the one hand, the possibility of the introduction of new steel products, on the other hand, the competitiveness of other construction materials, it is necessary to determine the program of development of products and technologies for their production.

3. Development of new steel products and steel grades with the prospect of the implementation of the 2030

Product development is one of the most important ways to increase the competitiveness and attractiveness of steel as compared to other engineering materials. New steel products should be offered to users along with customized properties of these technologies, forming, cutting and machining and joining [12-17]. Product development involves the modification of production technology and therefore research on the design of steel products with new or improved properties include also - to varying degrees depending on the individual case - improving or modifying the technology of steel billets and steel products and processing technology to adapt to the new properties of the products [18-28]. If new properties of steel or steel with the participation of technologies affect their formation, machining or welding, a new assortment of products should be offered to users along with the modified technology of processing.

The goal of paper is presents the potential of the advanced computational methods, the fuzzy systems in this case, for determination of the Jominy hardenability curve based on the

* SILESIAN UNIVERSITY OF TECHNOLOGY, DIVISION OF BIOMEDICAL ENGINEERING, INSTITUTE OF ENGINEERING MATERIALS AND BIOMATERIALS,, 18 A KONARSKIEGO STR., 44-100 GLIWICE, POLAND

\# Corresponding author: wojciech.sitek@polsl.pl 
chemical composition of structural steels for quenching and tempering. Fuzzy system was developed to calculate hardness of the steel, based on the alloying elements concentrations, and to forecast the Jominy hardenability curves.

\section{Structural steels for quenching and tempering}

Steels for quenching and tempering are designed to produce machine parts quenched and tempered - hardened (induction, flame), which are under high mechanical loads during exploitation. These are for example shafts, gears, bolts and rods. Hardened steels have increased $R_{m}$ (tensile strength) in the range from 600 to $1100 \mathrm{MPa}$.

Alloying elements allow to obtain high mechanical properties of parts with large cross sections trough increasing the hardenability. Medium or high hardenability is expressed by critical diameter characterizing this group of steels and amount 30 to $80 \mathrm{~mm}$.

Most steels for quenching and tempering are low-alloy steels with a total concentration of alloying elements not more than 3\%. There are also medium-alloy steels (3-5\% alloying elements) and a small number of steels having a concentration of elements above $5 \%$.

In the cheapest steels manganese is used to increase hardenability. However, it conduces growth of austenite grains during hardening. Manganese can be partially replaced by silicon which is conductive to fine-grained austenite. Manganese steels are used for shafts, axles, screws, and silicon-manganese steels for the parts to be abraded. Chromium steels are used for high-loaded shafts, axles, connecting rods and other machine parts with small cross sections, and steels with the addition of molybdenum for machine parts with large cross sections.

Steels for quenching and tempering are hardened from $820-900^{\circ} \mathrm{C}$ temperatures. High tempering is carried out at $540-680^{\circ} \mathrm{C}$, and in the case of steel with boron microalloying at $400-600^{\circ} \mathrm{C}$. The concentration of carbon and carbideforming elements determine the tempering temperature. The higher concentration of these elements, the higher tempering temperature.

These steels are hardened to ensure needed properties, therefore is required to determine their hardenability. The most commonly used method is Jominy test (Fig. 1) in which heated steel bar is quenched from one end with jet of water. After cooling, the hardness is measured at intervals taken from the quenched end. Hardenability curve shows the results of the test. It is a graph of hardness versus distance from the quenched end.

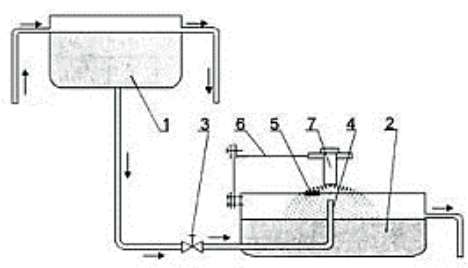

Fig. 1. Scheme of the Jominy Testing Device (1 - water tank, $2-$ tub, 3 - valve, 4 - water nozzle, 5 - aperture, 6 - sample holder, 7 - sample)

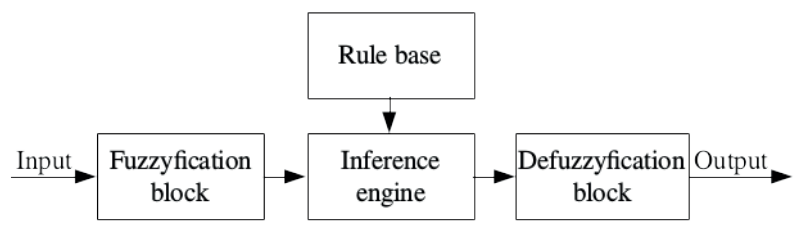

Fig. 2. Scheme of the fuzzy system

Due to the differences in the allowable concentration of alloying elements hardenability test results obtained for the same kind of steel differ from each other. The area between the minimum and maximum values for the one kind of steel is called hardenability band.

\section{Fuzzy systems}

Fuzzy systems are based on fuzzy logic and allow a description of reality with its inaccuracy and ambiguity. Fuzzy systems at the input can accept both: numerical data and linguistic values. The inputs of the system, depending on their type, can be fuzzed and reach a conclusion based on rules. The result is sharpened and given on the output of the system. In other words, the input values (facts) are converted by the system in the outputs based on the rules.

Fuzzy systems (Fig. 2.) are composed of several parts called blocks: fuzzyfication (blurring) block, defuzzyfication (sharpening) block, rule base (also called a knowledge base) and inference machine (also known as the inference engine). At the input of the system are given some values which may be either numerical or linguistic. For the fuzzy system numerical values must be blurred, while the linguistic values which are put to the system as fuzzy sets can skip this step [29,30]. The rule base in each fuzzy system is made in the of Eq. (1) of conditional if-then rules:

$$
\operatorname{IF}\left(x_{1}=A_{1}\right) A N D\left(x_{2}=B_{1}\right) \text { THAN }\left(y=C_{1}\right)
$$

Inference machine, based on the theory of fuzzy sets and fuzzy inference. This block performs the purpose of creating systems, i.e. converts the given input values to the output values with using the rule base $[29,30]$.

Historically, the first fuzzy system was system created by E.H. Mamdani and S. Assilan, which was in 1975 practically applied. It based on the Zadeh's work and was relatively simple and clear, whereby quickly gained popularity. The described problem is treated as a black box, in which there is no information about the modelled phenomenon. Authors applied on their system operation minimum for modelling the connective "and" in the condition and the conjunctive interpretation of the rules. For the results aggregation from inference is used the maximum operation, and numeric input are treated as fuzzy singletons. Knowledge base for MamdaniAssilan system (in short MA) is obtained from a human-expert. Rules contained therein define single fuzzy points forming together a graph $[29,30]$.

Another fuzzy system is system proposed by Takagi, Sugeno and Kang, in which there are a functional dependences in conclusions. It is suitable to describe the laws of physics, for example for air resistance, which phenomenon is so 
complicated that it is difficult to analytical description. For this phenomenon there are only empirical laws describing the dependence of air resistance on velocity (different law for different velocity) - rules of the TSK system (short for TakagiSugeno-Kang) model them well. Canonical form Eq. (2) of the rules in this system is as follows:

$$
R^{(i)}=\left\{I F \bigwedge_{n=1}^{N} x_{0 n} I S A_{n}^{(i)}, T H A N y=f_{i}\left(\mathbf{x}_{0}\right)\right\}
$$

where:

$x_{0 n}$ - input singleton,

$y=f_{i}\left(\mathbf{x}_{0}\right)$ - function in conclusion of rule $R^{(i)}$

$A_{1}^{(i)}, A_{2}^{(i)}, \ldots, A_{N}^{(i)}$ - fuzzy sets being linguistic values which belong to $A_{n}^{(i)} \subseteq X_{n}, \mathbf{x}_{0}=\left[x_{01}, x_{02}, \ldots, x_{0 N}\right]^{T}$.

Function in conclusions may depending on the implementation of the system, but most often is used a first degree polynomial. Due to the linear function, obtain firstorder TSK fuzzy system, also sometimes called Sugeno, which is used mainly to problems with fuzzy singletons inputs. TSK fuzzy system is more difficult to understand than the MA system because of computational complexity. However, this system is very well suitable to the description of regulators and complicated processes. TSK system allows for the implementation of expert knowledge for the distribution of inputs and outputs. Fig. 3 presents diagram of the TSK fuzzy system $[29,30]$.

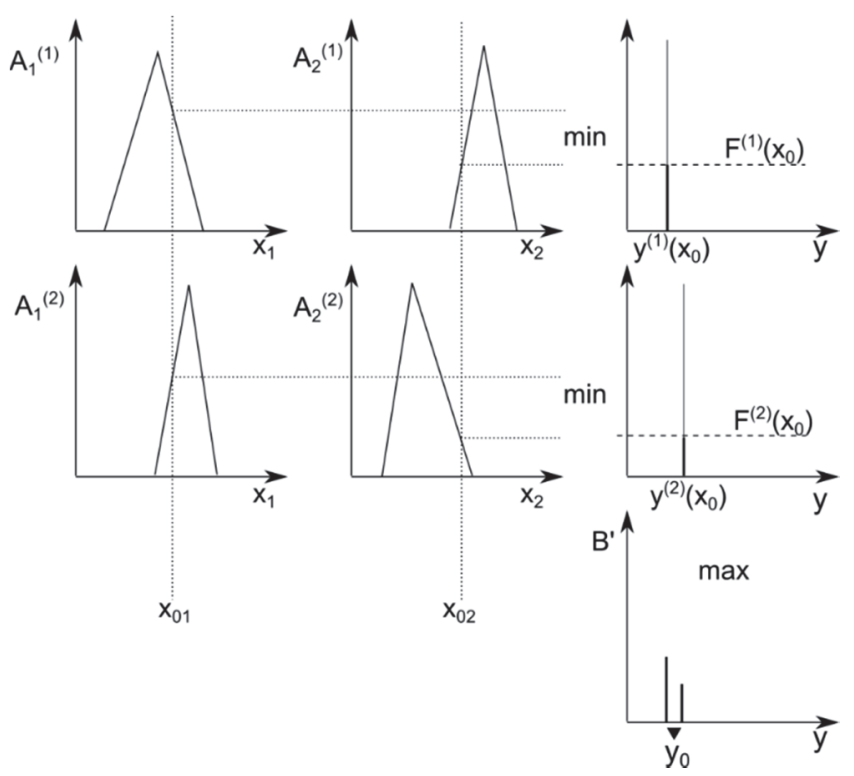

Fig. 3. Scheme of exemplary TSK fuzzy system

Another concept of fuzzy system also presented J. Łęski and E. Czogała [31,32], so-called fuzzy system with moving consequents in if-then rules. It is called so because the position of the sets in conclusions is a function of the input singletons.
When the input are fuzzy sets - which aren't a single value, the position of sets in conclusions may depend on inputs parameters such centre of mass or height.

The disadvantage of this system is difficulties with obtaining the rule base with the proper conclusions from the human expert, but it can be automatically extracted from numerical data. Fuzzy system with parametric conclusions can be understood as a council of experts. Each expert (one rule) gives his answer for a given input, than the common response is a weighted average of all responses [29].

\section{Numerical studies}

In the process of designing construction engineer must consider many externals that interact at the same time on the item. Therefore, it is necessary to reconcile all the criteria so that the produced constructions perform its role properly. The possibility of the steel production with specific mechanical properties makes it not difficult to manage these criteria one of the mechanical properties under consideration is the hardness of steel, which is affected by the alloying elements.

The aim was to create a fuzzy system which will be allow the calculation of the hardness of the steel based on a given chemical composition and the distance from the quenched end, as well as to predict the hardenability curves which are the chart of hardness versus the distance from the hardened surface. Steels for quenching and tempering from PN-EN 10083-3:2008 used to create a system. From this norm used the upper and lower limits of the band hardenability and distance in $\mathrm{mm}$ from the quanched-end.

Prepared database which was used to prepare the fuzzy system contains the following elements: C (carbon), $\mathrm{Cr}$ (chromium), Ni (nickel), Si (silicon), Mn (manganese), Mo (molybdenum), V (vanadium) and B (boron), and the distance (in $\mathrm{mm}$ ) from the quenched end. Output variable is hardness of the steel expressed in HRC. Limit values of input and output variables are shown in table 1.

Prepared database which was used to prepare the fuzzy system contains the following elements: C (carbon), $\mathrm{Cr}$ (chromium), Ni (nickel), Si (silicon), Mn (manganese), Mo (molybdenum), V (vanadium) and B (boron), and the distance (in $\mathrm{mm}$ ) from the quenched end. Output variable is hardness of the steel expressed in HRC. Limit values of input and output variables are shown in table 1.

From the data available in the database were selected 30 random values, which were the test set for verifying the operation of the developed systems for the input values (chemical composition). These data weren't used for developed the systems.

From the available systems to research was used TakagiSugeno-Kang fuzzy system, which is well suitable to describe the phenomena difficult to determine analytically, for which

TABLE 1

Limit values of variables

\begin{tabular}{|c|c|c|c|c|c|c|c|c|c|}
\hline \hline & $\mathrm{C}, \%$ & $\mathrm{Cr} \%$ & $\mathrm{Ni}, \%$ & $\mathrm{Si} \%$ & $\mathrm{Mn}, \%$ & $\mathrm{Mo} \%$ & $\mathrm{~V}, \%$ & $\mathrm{~B}, \%$ & $\begin{array}{c}\text { Distance from } \\
\text { quenched end, mm }\end{array}$ \\
\hline Minimum & 0.17 & 0 & 0 & 0.13 & 0.3 & 0 & 0 & 0 & 1.5 \\
\hline Maximum & 0.55 & 2.2 & 2.2 & 0.4 & 1.7 & 0.5 & 0.25 & 0.005 & 25 \\
\hline
\end{tabular}


there is only empirical laws. This is due to the functional dependencies in the conclusions of if-then rules of the TSK system.

Taken into account was also the Mamdani-Assilan system because of ease understanding by less mathematical complexity than the system TSK. However, this system manage worse with the empirical data, because it is focused on the acquisition of knowledge from human-expert. The problem, which is the subject of this paper is too complicated to be able to be effectively described by the MA system.

As well as TSK system to describe phenomena known only empirical laws, suitable is fuzzy system with moving consequents in if-then rules. However, this system is equivalent of TSK when in the fuzzy if-then rules are singletons - which is in this paper. Parametric conclusions also complicate the system and increases the difficulty of its implementation.

The fuzzy system was created using MATLAB $\AA$ Mathworks TM version R2014a. It was used also an additive Fuzzy Logic Toolbox, which allows in MATLAB fuzzy logic and provides the functions associated with fuzzy systems.

Fuzzy system was created using function genfis2, which generates the FIS (Fuzzy Inference System) Sugeno type. FIS is a structure which is inferring fuzzy system MISO type (multiple input, single output). The number of if-then rules with the conclusions contain polynomial functions can be determined in advance or automatically calculated (adjusted for the amount of data), and is equal to the number of clusters (groups of objects with a common centre, separated from the whole), on which were divided the data base.

Automatic selection of the number of clusters was made by subclust function which is a fast, one-pass algorithm for estimating the number of clusters and the cluster centres in a set of data (element of Matlab Fuzzy Logic ToolBox). Subtractive clustering method select from the measurement points a some amount of potential clusters, for which is calculated a measure of density - the highest value determines the first cluster centre. Then the measure of density is calculated again for all points: if the point is closer to the first calculated cluster centre than it have a lower measure of density. The next cluster centre is again a point with the highest value. Iterations are repeated until all data are assigned to clusters.

Subclust function allows to define the range of the impact of the cluster centre in each dimension, what affects their size. It also allows to determine factors that affect possibility to be the point the new centre.

FIS created in this way contains if-then rules, each of which describe a single cluster. For modelling of the process of inference in MATLAB, can be used the following methods:

- the conjunction "and" can be modelled by min method, which "cut" the output fuzzy set or by prod method, which scales the output (flatten),

- operator "or" can be modeled by max method, which takes into account the highest value or by method probor (probabilistic OR, also known as the algebraic sum),

- $\quad$ to the implication is used min or prod method (standard Matlab Function),

- the aggregation of all the rules responses can be done by max, probor or sum (the sum of the outputs of each rule)
- $\quad$ to the deffuzzification can be used 5 methods: centroid, bisector, middle of maximum, largest of maximum and smallest of maximum, wtaver (weight average) and wtsum (weight sum), of which the most popular is centroid - defining the centre of gravity under the curve after the aggregation, for the MA system and wtaver for TSK system.

The created FIS can be edited by entering appropriate commands or by using the graphical FIS Editor. This editor allows to edit the fuzzy rules, the add and remove the input and output variables, edit the membership function, and also displays the response of the system with the given values in the form of the level of rules activation or graph.

During creating the model assumes some simplifications. For low hardness values assume the minimum values of elements concentrations, and for the high HRC values assume their highest percentages - what result from the fact that each of these elements increases the hardness of the steel with the increase its concentration. The same was for the calculated average values of hardness.

For each mathematical model which is based on the numerical data base (eg. artificial neural networks), its scope should be limited to the input data, on which it was created. Similarly, in the case of this fuzzy system, the scope of which equals to the limit of elements concentration and to the distance from quenched end.

\section{Results}

In the study, was analysed many combinations of parameters (eg. the size of the cluster, the range of impact of the cluster centre), which allowed to the creation of many fuzzy systems with the varying quality. They allow to obtain a response with different accuracy and everyone else manage with the calculation of hardenability curve. From among of created systems were selected four, for which statistics are shown in table 2.

As can be see systems have a different number of rules (24 to 48), what affect the quality of the fuzzy system, for example on the responses given by the program. The input value of each variable belongs to these membership functions (example in Fig. 4) to some extent (0 to 1), activating each of them. Each membership function is also taken into account in the premises of rules, based on which reach a conclusions by applying the appropriate operator for all inputs. In the case of this system the operator was a "and" conjunction, which uses the max method. The resulting value is inserted into the previously created polynomial functions, which are the conclusions of if-then rules. Then the calculated values are sharpened by wtaver method, which is a weighted average of all responses of each rule.

The calculated hardness of steel for the given elements concentrations and the distance from quenched end can be known for few ways. One of them is to enter an appropriate command in the program. Also the respond of the created fuzzy system can be viewed as a diagram, which shows the activation level of each membership functions in rules for all inputs and the functions values of the conclusions. 
Very useful feature is the possibility to shown the hardenability curve. This dependence hardness versus distance from quenched end allows prediction of this property for a given kind of steel with predetermined concentrations of elements. Examples of such use of fuzzy system are shown in Fig. $5-8$, the kind of steel with elements concentrations is given in table 3 .

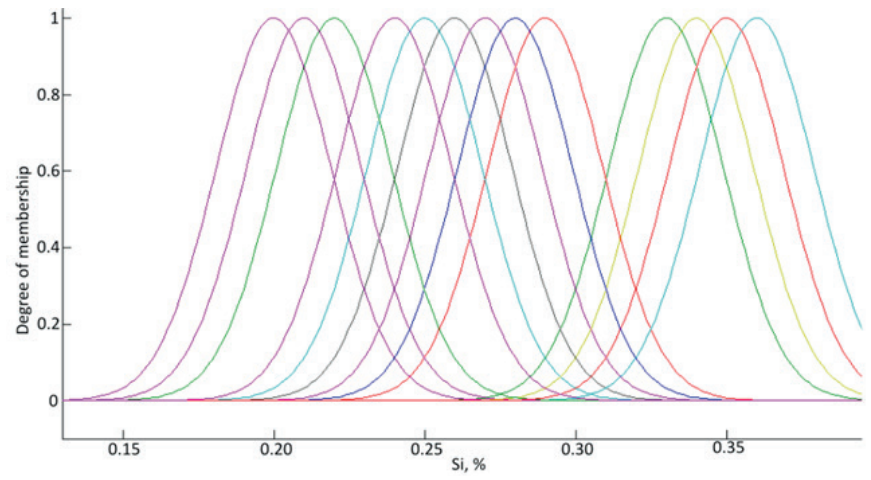

Fig. 4. The membership function of Si variable

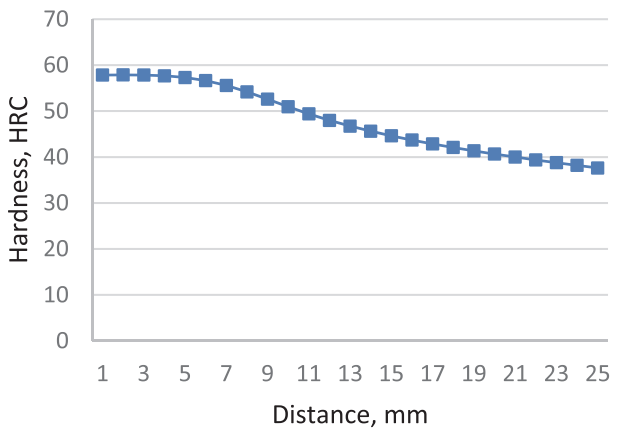

Fig. 5. The hardenability curve of steel $41 \mathrm{Cr} 4$

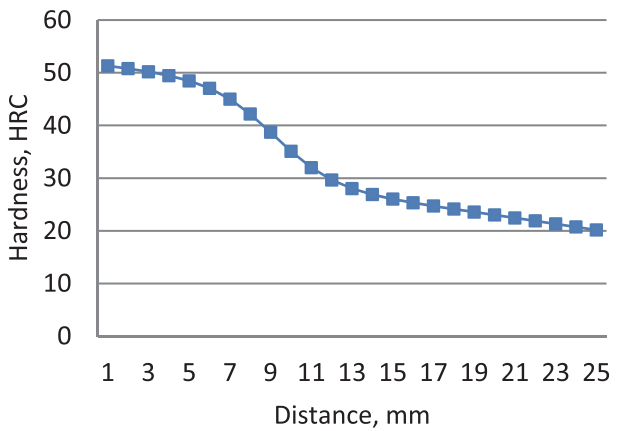

Fig. 6. The hardenability curve of steel $38 \mathrm{Cr} 2$

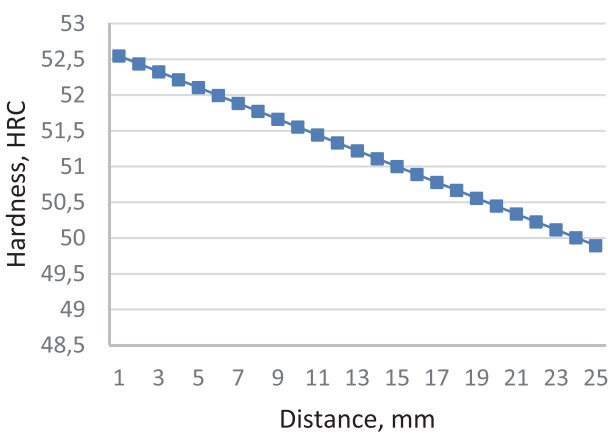

Fig, 7. The hardenability curve of steel $30 \mathrm{CrNiMo} 8$

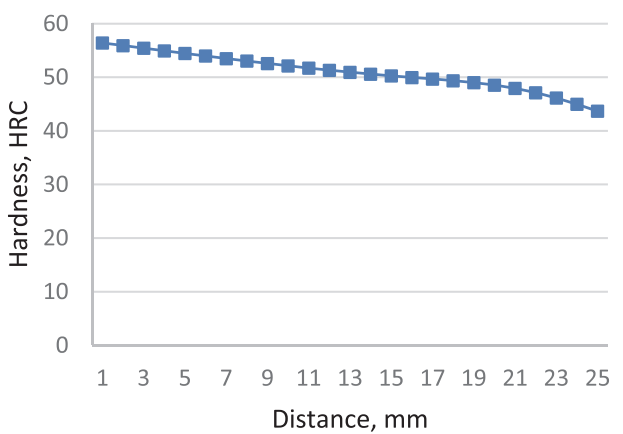

Fig. 8. The hardenability curve of steel 50CrMo4

TABLE 2

The statistics of selected fuzzy systems

\begin{tabular}{|c|c|c|c|c|}
\hline \hline & System 1 & System 2 & System 3 & System 4 \\
\hline Number of rules & 27 & 48 & 1.33 & 24 \\
\hline Mean absolute error, HRC & 1.53 & 1.19 & 0.99 & 0.98 \\
\hline Correlation coefficient & 0.98 & 0.99 & 1.35 & 1.40 \\
\hline Standard deviation, HRC & 1.38 & 1.27 & 7.76 & 8.16 \\
\hline Maximum absolute error, HRC & 9.42 & 8.39 & & \\
\hline
\end{tabular}

The chemical compositions of steels with hardenability curves shown in figures $5-8$

\begin{tabular}{|c|c|c|c|c|c|c|c|c|}
\hline \hline Steel grade & $\mathrm{Cr}, \%$ & $\mathrm{Si}, \%$ & $\mathrm{Mn}, \%$ & $\mathrm{Mo}, \%$ & $\mathrm{Ni}, \%$ & $\mathrm{~V}, \%$ & $\mathrm{~B}, \%$ & $\mathrm{C}, \%$ \\
\hline $41 \mathrm{Cr} 4$ & 1.04 & 0.34 & 0.72 & 0.04 & 0.13 & 0 & 0 & 0.42 \\
\hline $38 \mathrm{Cr} 2$ & 0.3 & 0.4 & 0.7 & 0 & 0 & 0 & 0 & 0.39 \\
\hline $30 \mathrm{CrNiMo} 8$ & 2 & 0.4 & 0.45 & 0.4 & 2 & 0 & 0 & 0.3 \\
\hline $50 \mathrm{CrMo} 4$ & 0.9 & 0.4 & 0.5 & 0.15 & 0 & 0 & 0 & 0.46 \\
\hline
\end{tabular}




\section{Conclusions}

The research on the development of fuzzy system with different parameters and their analysis allowed to formulate the following conclusions:

- The bigger number of rules in fuzzy system doesn't always increase the its accuracy, but can lead to overfitting the system, which isn't able to give acceptable answers for the test data.

- The size and shape of clusters have the impact on the quality of fuzzy rules, based on which reach to inference. Rule base describes these clusters.

- In the individual cases the results differed significantly from the experimental data, but this occurred only for minimal and maximal examples that were model boundary. It is normal for this type of mathematical models.

- Much better than Mamdani-Assilan in the task, which was the subject of this paper, was the TSK fuzzy system. Due to the functional dependence in the conclusions of fuzzy rules, TSK system better handle with cases which cannot be described by the specific physical laws but empirical only.

- $\quad$ The fuzzy system deal very well with data on which it was created - in cases outside the scope of the model results were very different.

- The fuzzy systems are a good tool to approximate inference what is possible because of previously created if-then rules, which describe the phenomenon that is otherwise hard to describe.

- This computer tool, which was used in materials science for structural steels for quenching and tempering, could be successfully used for other materials and their properties. Fuzzy systems could be used also in other fields of science.

\section{Acknowledgment}

This publication was financed by the Ministry of Science and Higher Education of Poland as the statutory financial grant of the Faculty of Mechanical Engineering SUT.

\section{REFERENCES}

[1] L.A. Dobrzański, A. Grajcar, W. Borek, Mater Sci Forum. 638642, 3224-3229 (2010).

[2] L.A. Dobrzański, W. Borek, Arch Civ Mech Eng. 12, (3), 299304 (2012).

[3] L.A. Dobrzański, W. Borek, Mater Sci Forum. 706-709, $2053-$ 2058 (2012).

[4] M. Król, T. Tański, W. Sitek, Applied Mechanics and Materials, 2015, IOP Conf. Series: Materials Science and Engineering 95 (2015) 012006 doi:10.1088/1757-899X/95/1/012006.

[5] M. Krupinski, L.A. Dobrzanski, J.H. Sokolowski, W. Kasprzak,
G. Byczynski, Mater. Sci. Forum 539-543,339-344 (2007).

[6] M. Krupinski, B. Krupinska, Z. Rdzawski, K. Labisz, T. Tanski, J Therm Anal Calorim 120(3), 573-583 (2015).

[7] Zieliński, G. Golański, M. Sroka, P. Skupień, Mater. High Temp. (2016), DOI: 10.1080/09603409.2016.1139306 (in press).

[8] Zieliński, G. Golański, M. Sroka, T. Tański, Mater. High Temp. (2015), DOI: 10.1179/1878641315Y.0000000015 (in press).

[9] Zieliński, G. Golański, M. Sroka, J. Dobrzański, Mater. Sci. Tech-Lond. (2015), DOI: 10.1179/1743284715Y.0000000137 (in press).

[10] Zieliński, G. Golański, M. Sroka, Kovove Mater. 54, (1) 51-58 (2016).

[11] R. Bidulsky, M.A. Grande, A. Zago, Z. Brytan Z., J. Bidulska, Arch. Metall. Mater. 55(3), 623-629 (2010).

[12] A. Lisiecki, Metals 5(1), 54 (2015).

[13] A. Lisiecki, Titanium Matrix Composite Ti/TiN Produced by Diode Laser Gas Nitriding, Metals 5(1), 54-69 (2015), doi:10.3390/met5010054.

[14] A. Kurc-Lisiecka, et al, Sol. St. Phenomena 203-204, 105 (2013).

[15] A. Lisiecki, Proceedings of SPIE, Laser Technology 2012: Application of Lasers, 8703 (2013), doi:10.1117/12.2013431

[16] A. Lisiecki, Proceedings of SPIE, Laser Technology 2012: Applications of Lasers, 8703 (2013), doi:10.1117/12.2013429

[17] A. Lisiecki, Welding of titanium alloy by Disk laser, Proceedings of SPIE, Laser Technology 2012: Application of Lasers, 8703 (2013), doi:10.1117/12.2013431.

[18] L.A. Dobrzanski, J. Madejski, W. Malina, W. Sitek, J Mater Process Tech. 56 (1-4), 873-881 (1996).

[19] L.A. Dobrzanski, W. Sitek, J Mater Process Tech. 64 (1-3), 117-126 (1997)

[20] L.A. Dobrzanski, W. Sitek, J Mater Process Tech. 90, $467-$ 472 (1999)

[21] L.A. Dobrzanski, W. Sitek, J Mater Process Tech. 164 (1-3), 1607-1611 (2005)

[22] L.A. Dobrzanski, W. Sitek, J Mater Process Tech. 157, 245 249 (2004).

[23] L.A. Dobrzanski, W. Sitek, M. Krupinski, et. al. J Mater Process Tech. 157, 102-106 (2004).

[24] W. Sitek, J. Trzaska, Mater Sci Forum 575-578, 829-897 (2008).

[25] W. Sitek, TRANS FAMENA 34 (3), 39-46 (2010).

[26] L.A. Dobrzański, M. Drak, J. Trzaska, J Mater Process Tech. 192, 595-601 (2007)

[27] L.A. Dobrzański, M. Drak, J. Trzaska, J Mater Process Tech. 164-165, 795-804 (2005).

[28] L.A. Dobrzański, T. Tański, J. Trzaska, Mater Sci Forum 638 , 1488-1493 (2010).

[29] J. Lęski, Neuro-fuzzy systems, Wydawnictwo NaukowoTechniczne, Warszawa 2008 (in polish)

[30] R.R. Yager, Principles of fuzzy modeling and control, Wydawnictwo Naukowo-Techniczne, Warszawa 1995 (in polish).

[31] J. Łęski, E. Czogała, Fuzzy Set Syst. 108, 289 - 297 (1999).

[32] J. Łęski, E. Czogała, BUSEFAL 71, 72 - 81 (1997). 